\title{
Diferentes tratamentos de sementes sobre o desenvolvimento de plantas de soja
}

\author{
Different treatments of seeds on the development of soybean plants
}

\author{
Ricardo Pereira da Cunha ${ }^{I^{*}}$ Marciabela Fernandes Corrêa ${ }^{I}$ \\ Luis Osmar Braga Schuch ${ }^{\mathrm{I}}$ Roberto Caetano de Oliveira ${ }^{\mathrm{I}}$ José de Souza Abreu Junior $^{\mathrm{I}}$ \\ Jéssica Dias Gomes da Silva ${ }^{\mathrm{I}}$ Tainan Lopes de Almeida
}

\section{RESUMO}

A cada ano são descobertos e utilizados novos produtos para o tratamento de sementesna cultura da soja (Glycine $\max$ L. Merril), visando aumentos de produção. Há a necessidade de conhecer a influência desses produtos sobre o desenvolvimento das plantas, a fim de obter sucesso na atividade. O objetivo do experimento foi avaliar o efeito de principais produtos aplicados via tratamento de sementes, sobre a morfologia de plantas de soja, em diferentes fases de desenvolvimento da cultura, bem como, sobre os componentes do rendimento e produtividade. Os produtos utilizados foram: tiametoxan; [abamectina +tiametoxan + fludioxonil]; [fipronil + tiofanatometilico + piraclostrobina]; [imidacloprido + tiodicarbe]; CruiserAdvanced ${ }^{\mathbb{}}$; carboxamida; abamectina; [metalaxyl-M + fludioxonil]; além da testemunha sem tratamento. Na primeira etapa, avaliou-se a qualidade fisiológica das sementes tratadas. Posteriormente, avaliou-se o crescimento inicial aos 15 , 30 e 45 dias após a emergência. Na terceira etapa, avaliaramse características agronômicas e componentes de rendimento. $O$ delineamento experimental utilizado para os testes fisiológicos das sementes foi inteiramente casualizado e para as determinações de desenvolvimento inicial e de final de ciclo, blocos ao acaso. Para análise estatística, utilizou-se o programa SASM-Agri. Concluiuse que a mistura de ingredientes ativos inseticidas e fungicidas prejudica o desenvolvimento inicial das plântulas de soja. Aos 45 dias após a emergência, há efeito positivo dos produtos tiametoxan,

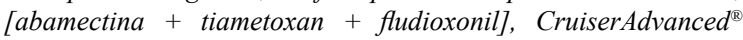
$e$ [metalaxyl-M + fludioxonil] sobre o crescimento, porém este estímulo não se reflete na produção final.

Palavras-chave: Glycine max (L). Merril, inseticidas, crescimento, produção.

\section{ABSTRACT}

Every year, new products are discovered and used for seed treatment in soybeans (Glycine max. L. Merril), aiming to increase production. There is the need to know the influence of the products on the development of plants in order to be succeed in the activity. The aim of the experiment was to evaluate the effect of products applied as seed treatment on the morphology of soybean plants at different stages of crop development, as well as the components of income and productivity. The products used were: tiametoxan; [abamectina + tiametoxan + fludioxonil]; [fipronil + tiofanatometilico + piraclostrobina]; [imidacloprido + tiodicarbe]; Cruiser Advanced ${ }^{\mathbb{E}}$; carboxamida; abamectina; [metalaxyl-M + fludioxonil]; and the control without treatment. In the first step, it was evaluated the physiological quality of treated seed. Subsequently, it was evaluated the initial growth at 15, 30 and 45 days after emergence. In the third stage were evaluated agronomic traits and yield components. The experimental design used for physiological tests of the seeds was randomized and the measurements of early development and late season, were randomized blocks. For statistical analysis, it was used the program SASM-Agri (CANTERI et al., 2001). It was concluded that the mixture of active ingredients insecticides and fungicides affect the early development of soybean seedlings. At 45 days after emergence, there is a positive effect of the products Tiametoxan, [abamectina + tiametoxan + fludioxonil], Cruiser Advanced ${ }^{\mathbb{}}$ and [metalaxyl-M + fludioxonil] on growth, but this stimulus, is not reflected in the final production.

Key words: Glycine max (L.) Merrill, insecticides, growth, production.

\section{INTRODUÇ̃̃O}

O sucesso naprodução de sementes de soja (Glycine max L. Merril) e obtenção de uma lavoura com população adequada de plantas depende da correta utilização de diversas práticas culturais, estando à eficiência destas condicionada à utilização de sementes de boa qualidade. Algumas técnicas, como o tratamento de sementes, visam

\footnotetext{
IDepartamento de Fitotecnia, Universidade Federal de Pelotas (UFPel), 96001-970, Pelotas, RS, Brasil. E-mail: rpcunha@yahoo.com.br. ${ }^{*}$ Autor para correspondência. 
à melhoria e/ou manutenção da sua qualidade. Segundo LAUXEN et al. (2010) em algodão, BALARDIN et al. (2011) em soja, ALMEIDA et al. (2011) em arroz, tal prática apresenta eficiência, pois assegura populações adequadas de plantas, quando as condições edafoclimáticas durante a semeadura são desfavoráveis à germinação e à rápida emergência, concordando com HENNING (2005). Além disso, apresenta custo relativamente baixo e impacto ambiental reduzido, devido à área que recebe produto ser pequena, se comparada à aplicação de agroquímicos em parte aérea.

Alguns produtos como inseticidas de atuação fisiológica, podem promover crescimento mais vigoroso e com melhor aproveitamento do seu potencial produtivo (CASTRO et al., 2008). A cada ano são descobertos e utilizados novos ingredientes ativos para o tratamento de sementes de soja (MENTEN et al., 2010). Porém, há a necessidade de estudos sobre a influência destes, na qualidade física, fisiológica e sanitária das sementes. Nesse contexto, o presente trabalho teve por objetivo, avaliar o efeito fitotônico de ingredientes ativos aplicados via tratamento de sementes sobre a qualidade fisiológica, ocrescimento inicial das plantas e a produtividadede grãos em plantas de soja.

\section{MATERIAL E MÉTODOS}

O trabalho foi desenvolvido na Área Experimental (Latitude -31,8029, Longitude -52,4070) e Didática e no Laboratório Didático de Análise de Sementes do Departamento de Fitotecnia da Faculdade de Agronomia Eliseu Maciel, da Universidade Federal de Pelotas, localizados no município de Capão do Leão-RS. Utilizaram-se sementes de soja, cultivar 'NA5909RG'. As sementes foram tratadas com os produtos (Tabela 1) e doses descritos a seguir, com as doses calculadas para $100 \mathrm{~kg}$ de sementes. Tratamento 1 - tiametoxan (Cruiser ${ }^{\circledR} 350 \mathrm{FS}$ - 200mL); Tratamento 2 - [abamectina + tiametoxan + fludioxonil] (Avicta ${ }^{\circledR}$ Completo - 500mL); Tratamento 3 - [fipronil + tiofanatometilico + piraclostrobina] (Standak ${ }^{\circledR}$ Top 200mL); Tratamento 4 - [imidacloprido + tiodicarbe] $\left(\right.$ Cropstar $\left.^{\circledR}-250 \mathrm{~mL}\right)$; Tratamento 5-(CruiserAdvanced ${ }^{\circledR}$ 200mL); Tratamento 6 - carboxamida (Sedaxane ${ }^{\circledR}$ $150 \mathrm{~mL})$; Tratamento 7 - abamectina (Avicta ${ }^{\circledR}-100 \mathrm{~mL}$ ); Tratamento 8 - [metalaxyl-M + fludioxonil] $\left(\right.$ Maxim $^{\circledR} \mathrm{XL}$ $100 \mathrm{~mL}$ ); Tratamento 9 - testemunha (sem tratamento).

As sementes foram tratadas em saco plástico, contendo água destilada na proporção de
Tabela 1 - Modo de ação dos princípios ativos utilizados como tratamentos.

\begin{tabular}{lccc}
\hline Princípio Ativo & Inseticida & Fungicida & Nematicida \\
\hline Tiametoxan & $\mathrm{X}$ & & $\mathrm{X}$ \\
Abamectina & & $\mathrm{X}$ & \\
Fludioxonil & & & \\
Fipronil & $\mathrm{X}$ & $\mathrm{X}$ & \\
Tiofanatometilico & & $\mathrm{X}$ & \\
Piraclostrobina & & & \\
Imidacloprido & $\mathrm{X}$ & $\mathrm{X}$ \\
Tiodicarbe & $\mathrm{X}$ & $\mathrm{X}$ \\
Carboxamida & & $\mathrm{X}$ \\
CruiserAdvanced & $\mathrm{X}$ & \\
Metalaxyl-M $^{\circledR}$ & & & \\
\hline
\end{tabular}

$400 \mathrm{~mL}$ por $100 \mathrm{~kg}$ de sementes, mais o ingrediente ativo. Para a avaliação dos efeitos dos tratamentos sobre a qualidade fisiológica das sementes, realizaram-se os seguintes testes após a aplicação dos ingredientes ativos e secagem das sementes: Germinação: conforme as Regras para Análises de Sementes-RAS (BRASIL, 2009); Envelhecimento acelerado: conduzido com $4 \mathrm{~g}$ de sementes, distribuídas em tela de arame suspensa e colocadas no interior de caixas plásticas, tipo gerbox (mini-câmara), contendo $40 \mathrm{~mL}$ de água destilada. As caixas foram levadas a uma incubadora, regulada à temperatura constante de $41^{\circ} \mathrm{C}$, durante 48 horas, sendo as sementes posteriormente submetidas ao teste de germinação, conforme RAS (BRASIL, 2009); Comprimento radicular e de parte aérea: foram utilizadas quatro repetições de 20 sementes, semeadas intercaladas sobre duas linhas, traçadas no terço superior do papel. Os rolos contendo as sementes permaneceram a $25^{\circ} \mathrm{C}$ por sete dias, sendo avaliado, posteriormente, o comprimento radicular e de parte aérea das plântulas normais, com auxílio de uma régua milimetrada, sendo as médias expressas em centímetros; Massa seca radicular e de parte aérea: após a determinação dos comprimentos de parte aérea e raiz, as amostras seguiram para estufa de circulação forçada de ar, com temperatura de $65^{\circ} \mathrm{C}$ por 72 horas. As amostras foram pesadas em balanças de precisão com quatro casas decimais, sendo os valores expressos em miligramas.

A implantação do experimento para as avaliações de campo ocorreu em 07/12/2011, com semeadura realizada em oito canteiros de 0,5 metros de largura por cinco metros de comprimento. A adubação foi realizada conforme interpretação da análise de solo, seguindo a orientação da Rede Oficial 
de Laboratórios de Análises de Solo e de Tecido Vegetal dos Estados do Rio Grande do Sul e Santa Catarina (ROLAS), sendo as sementes inoculadas com Bradyrhizobium (200mL por $100 \mathrm{~kg}$ de sementes). As sementes foram semeadas em covas de $10 \times 10 \mathrm{~cm}$. Utilizaram-se nove sementes por cova, equidistantes umas das outras. O espaçamento entre covas foi de $40 \mathrm{~cm}$, sendo que cada cova representou uma unidade experimental. Aos 10 dias após a emergência, eliminaram-se as três plantas menos vigorosas, permanecendo seis plantas em cada parcela. A cada 15 dias, a partir da emergência das plantas, até os 45 dias, coletou-se uma planta, para a determinação do crescimento inicial. Estas foram cortadas com auxílio de tesoura, rente ao solo. As variáveis analisadas foram: Área Foliar: avaliada com a utilização de um determinador de área foliar modelo LI-3100; Altura de Planta: determinada com auxílio de régua milimetrada, tomando-se como base a distância desde o solo até o último trifólio em desenvolvimento; Diâmetro do Caule: determinado com auxílio de um paquímetro (centímetros e milímetros), na altura do nó cotiledonar, em sentido contrário à inserção destes; Massa Seca das Folhas e do Colmo: determinadas em gramas com auxílio de balança de precisão com duas casas, secas em estufa com circulação forçada de ar, à temperatura de $65^{\circ} \mathrm{C}$ por 72 horas.

As demais plantas (três) permaneceram nos canteiros para avaliações no final do ciclo (135 dias após a emergência). No momento em que as sementes alcançaram 14\% de umidade, realizouse a coleta de todas as plantas, sendo determinados os parâmetros: Altura de Planta: com o auxílio de régua milimetrada, tomando-se como base a distância desde o solo até a extremidade da nervura principal do folíolo central do último trifólio expandido; Número de Vagens por Planta: pela contagem manual; Diâmetro do Caule: com auxílio de um paquímetro; Número de Nós por Planta: através de contagem visual; Número de Sementes por Vagem; Peso de Mil Sementes: conforme as RAS (BRASIL, 2009) e Produtividade por Planta: expresso em gramas por planta. $\mathrm{O}$ delineamento experimental utilizado para os testes fisiológicos das sementes foi inteiramente casualizado, com nove tratamentos e quatro repetições. Para as determinações de desenvolvimento inicial e de final de ciclo, utilizouse o delineamento experimental de blocos ao acaso, com nove tratamentos e oito repetições. A análise estatística foi realizada com o auxílio do programa SASM-Agri (CANTERIet al., 2001), através de análise da variância e agrupamento de médias pelo teste de Scott-Knott a 5\% de probabilidade.

\section{RESULTADOS E DISCUSSÃO}

Em relação à germinação, observou-se comportamento semelhante entre os tratamentos para a variável germinação (Figura 1A), não havendo diferença significativaentre os tratamentos. Ocorreu uma exceção para o produto Cruiser Advanced ${ }^{\circledR}$ (T5), o qual provocou efeito negativo sobre a germinação das sementes. Para o teste de envelhecimento acelerado, observa-se, na figura $1 \mathrm{~A}$, que os tratamentos com tiametoxan, [abamectina + tiametoxan + fludioxonil], [imidacloprido + tiodicarbe], carboxamida, abamectina, [metalaxyl-M + fludioxonil], e a testemunha, sem tratamento, apresentaram o mesmo comportamento, não diferindo entre si. Resultados semelhantes foram constatados por CASTRO et al. (2008), os quais, trabalhando com diferentes inseticidas e um bioestimulante no tratamento de sementes de soja, observaram que o tratamento com imidacloprido não diferiu estatisticamente da testemunha sem tratamento. Para os inseticidas fipronil, tiametoxan e imidacloprido, DAN et al. (2010) observaram que a utilização de um ingrediente ativo isolado proporciona maior índice de velocidade de germinação, quando comparados com produtos combinados, como [imidacloprido + tiodicarbe]

Para comprimento de parte aérea (Figura 1B), os tratamentos com tiametoxan, [abamectina + tiametoxan + fludioxonil], abamectina, [metalaxyl-M + fludioxonil] não diferiram da testemunha sem tratamento. Os tratamentos com [fipronil + tiofanatometilico + piraclostrobina] e CruiserAdvanced ${ }^{\circledR}$ causaram redução no comprimento da parte aérea, juntamente com os tratamentos [imidacloprido + tiodicarbe] e carboxamida. Os dois primeiros produtos também causaram redução no desempenho das sementes, avaliado pelo envelhecimento acelerado. Já o comprimento radicular não foi afetado pelos diferentes tratamentos aplicados nas sementes (Figura 1B). Resultados semelhantes foram relatados por BALARDIN et al. (2011), quando utilizaram diversos inseticidas e fungicidas via tratamento de sementes, os quais observaram que o comprimento radicular não foi influenciado.

Em relação à massa seca de parte aérea, também não há diferença estatística entre os tratamentos, sendo que todos os tratamentos apresentaram comportamento similar à testemunha (Figura 1C). BALARDIN et al. (2011) observaram, em estudo similar, que o único tratamento que proporcionou incremento significativo na massa seca 


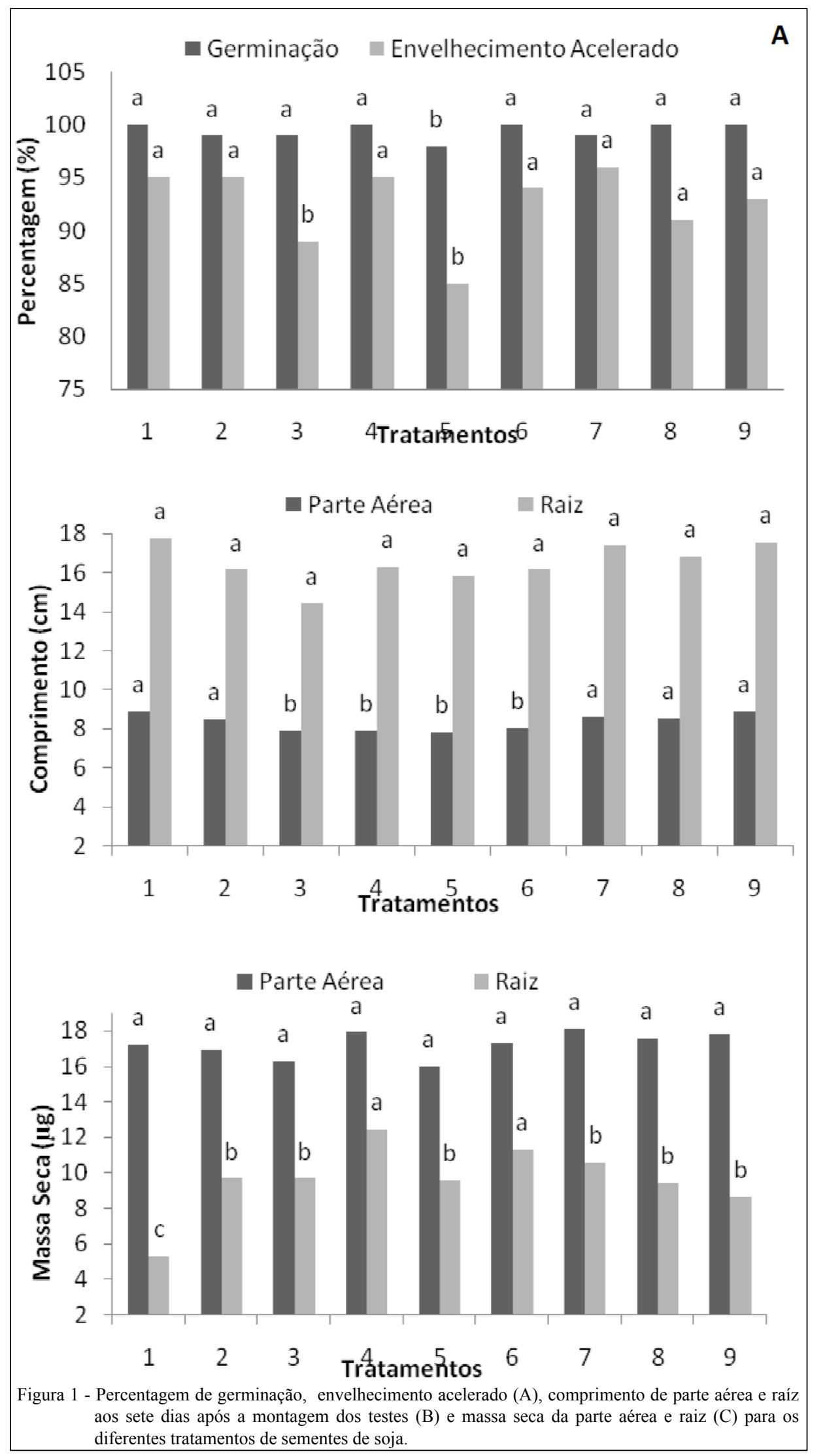

Ciência Rural, v.45, n.10, out, 2015. 
da parte aérea, entre todos os parâmetros avaliados foi [fipronil + tiofanatometílico + piraclostrobina].

Para massa seca de raiz, observou-se que os tratamentos com [imidacloprido + tiodicarbe] e carboxamida diferenciaram-se positivamente dos demais (Figura 1C), sendo que dentre todas as avaliações do potencial fisiológico, somente nesta variável, tratamentos com inseticidas e com fungicidas, sem a mistura de ambos, apresentaram comportamento superior à testemunha, sem tratamento. Este efeito merece destaque, pois o aumento da massa seca de raiz pode estar atrelado ao maior desenvolvimento de raízes secundárias, mais finas. Segundo NIELSEN \& BARBER (1978), sistemas radiculares mais finos têm geometria mais favorável à absorção de nutrientes pouco móveis no solo, com isso, as plantas podem se beneficiar com a absorção de nutrientes, como é o caso do fósforo.

$\mathrm{Na}$ primeira avaliação de desenvolvimento inicial em campo, realizada aos 15 dias após a emergência, não foi constatado efeito dos tratamentos para altura de planta e diâmetro de caule, conforme pode ser observado na tabela 2. Para área foliar e matéria seca

Tabela 2 - Altura de plantas, diâmetro do caule, área foliar, massa seca de folhas e caules, submetidas a diferentes tratamentos de sementes, aos 15, 30 e 45 diasapós a emergência. UFPel/2013.

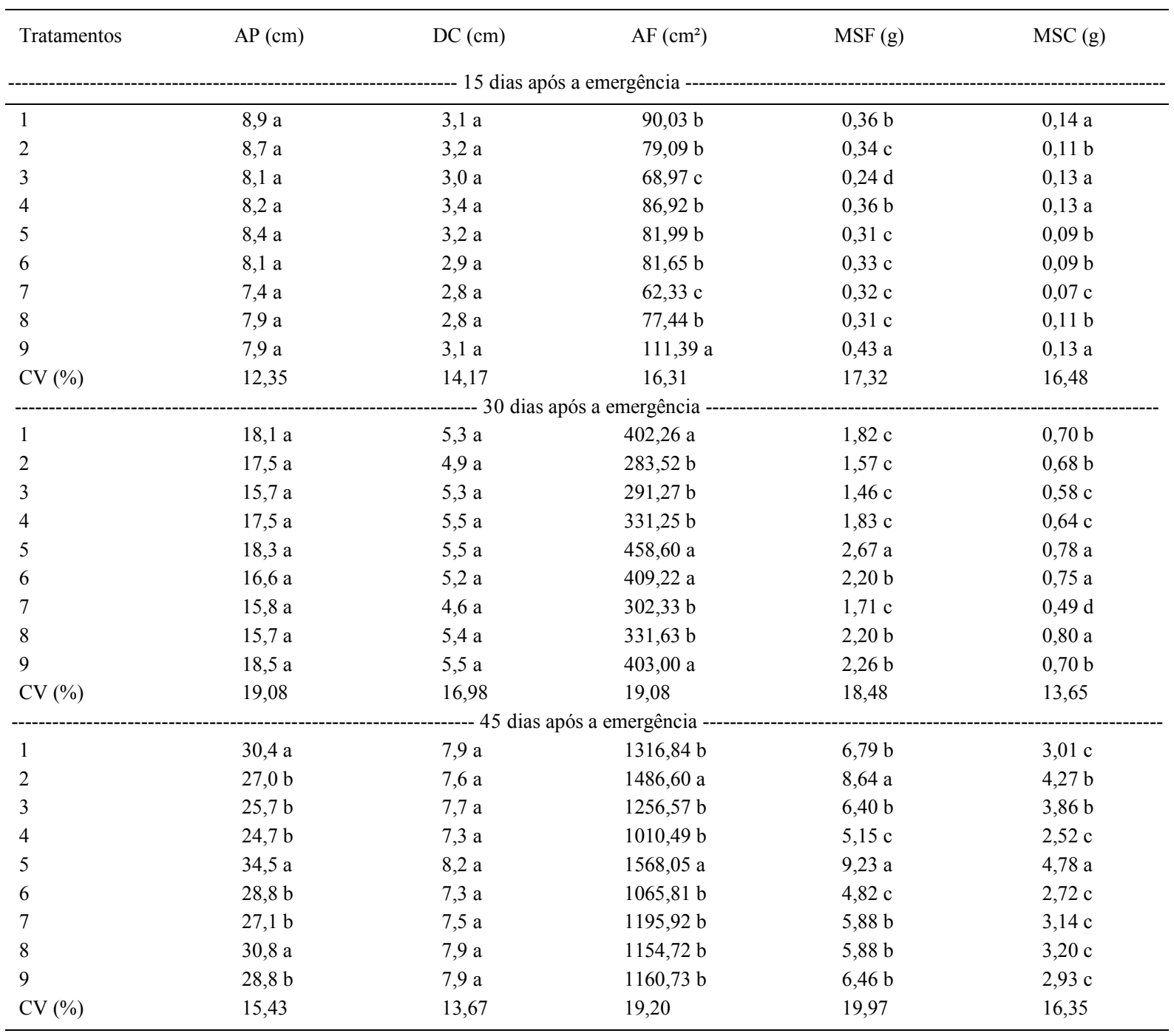

Médias seguidas da mesma letra nas colunas não diferem entre si pelo teste Scott-Knott a 5\%.

T1- tiametoxan (200mL por 100kg de sementes); T2- [abamectina + tiametoxan + fludioxonil] (500mL por 100kg de sementes); T3- [fipronil + tiofanatometilico + piraclostrobina] $(200 \mathrm{~mL}$ por $100 \mathrm{~kg}$ de sementes); T4- [imidacloprido + tiodicarbe] (250mL por $100 \mathrm{~kg}$ de sementes); T5- CruiserAdvanced ${ }^{\mathbb{B}}(200 \mathrm{~mL}$ por $100 \mathrm{~kg}$ de sementes); T6- carboxamida (150mL por 100kg de sementes); T7- abamectina (100mL por $100 \mathrm{~kg}$ de sementes); T8- [metalaxyl-M + fludioxonil] (100mL por 100kg de sementes); T9- testemunha (sem tratamento). 
de folhas, a testemunha apresentou os maiores valores, indicando que todos os produtos testados prejudicaram o crescimento inicial das plantas até 15 dias após a emergência. Para matéria seca de caule, observou-se que os produtos, tiametoxan, [fipronil + tiofanatometilico + piraclostrobina] e [imidacloprido + tiodicarbe] destacamse em relação aos demais, não diferindo, no entanto, da testemunha. Aos 30 dias após a emergência, também não ocorreu diferenças significativas entre os tratamentos, para as variáveis altura de planta e diâmetro de caule (Tabela 2). Já para a variável área foliar, os produtos tiametoxan, CruiserAdvanced ${ }^{\circledR}$ e carboxamida não apresentaram efeito prejudicial, uma vez que apresentaram comportamento semelhante à testemunha, sem tratamento. Tais resultados contrariam as observações de CLAVIJO (2008), o qual observou aumento da área foliar, maior uniformidade na emergência e melhor desenvolvimento inicial em plantas de soja, oriundas de sementes tratadas com inseticida tiametoxan. Os demais produtos prejudicaram o desenvolvimento de área foliar no período de até 30 dias após a emergência da cultura.

O tratamento com CruiserAdvanced ${ }^{\circledR}$ proporcionou acréscimo na produção de matéria seca de folhas (Tabela 2), superando todos os demais tratamentos. Para produção de matéria seca do caule, novamente o produto CruiserAdvanced ${ }^{\circledR}$, juntamente com os produtos a base de carboxamida e [metalaxyl-M + fludioxonil] mostraram-se superiores à testemunha. Segundo CASTRO et al. (2007), os inseticidas e fungicidas são desenvolvidos visando à eficiência no controle de pragas e doenças, sendo que alguns podem provocar efeitos ainda pouco conhecidos, capazes de modificar o metabolismo e a morfologia vegetal. Aos 45 dias após a emergência o produto CruiserAdvanced ${ }^{\circledR}$ apresentou maior produção de matéria seca do caule (Tabela 2), superando a testemunha sem tratamento. $\mathrm{O}$ efeito benéfico deste produto sobre o crescimento de plantas de soja pode ser observado nas demais variáveis, com exceção do diâmetro de caule, onde todos os produtos apresentaram comportamento semelhante entre si e com a testemunha.

Em relação às características agronômicas e componentes de rendimento (Tabela 3), pode-se notar a influência dos tratamentos somente para a variável número de sementes por vagem, na qual os produtos tiametoxan e [metalaxyl-M + fludioxonil] apresentaram comportamento superior aos demais produtos e à testemunha, mas sem diferirem entre si. Ainda, observou-se que nenhum dos produtos avaliados proporcionou acréscimos na produtividade de grãos nas plantas de soja. Observa-se que o peso de mil sementes não variou entre os tratamentos. Tal fato demonstra que a produção final é igual para ambos os produtos testados.

\section{CONCLUSÃO}

O tratamento de sementes de soja com os produtos testados mantém a qualidade fisiológica, genética e sanitária destas, apresentando efeitos benéficos em diversas fases do crescimento inicial e do desenvolvimento da cultura, porém sem efeito sobre a produção de grãos em plantas de soja.

Tabela 3 - Altura de plantas, número de vagens, diâmetro de caule, número de nós, número de sementes, peso de mil sementes e produtividade para os diferentes produtos. UFPel/2013.

\begin{tabular}{|c|c|c|c|c|c|c|c|}
\hline Tratamentos & $\mathrm{AP}(\mathrm{cm})$ & $\mathrm{NV} / \mathrm{pl}$ & $\mathrm{DC}(\mathrm{cm})$ & $\mathrm{NN} / \mathrm{Pl}$ & NS/Vag. & PMS (g) & Prod. (g.planta ${ }^{-1}$ ) \\
\hline 1 & $72,9 \mathrm{a}$ & $159 \mathrm{a}$ & $1,0 \mathrm{a}$ & $10 \mathrm{a}$ & $3 a$ & $184,08 \mathrm{a}$ & $72,28 \mathrm{a}$ \\
\hline 2 & $71,6 \mathrm{a}$ & $177 \mathrm{a}$ & $1,1 \mathrm{a}$ & $10 \mathrm{a}$ & $2 \mathrm{~b}$ & $192,55 \mathrm{a}$ & $69,32 \mathrm{a}$ \\
\hline 3 & $71,3 \mathrm{a}$ & $175 \mathrm{a}$ & $1,0 \mathrm{a}$ & $9 \mathrm{a}$ & $2 b$ & $204,98 \mathrm{a}$ & $72,17 \mathrm{a}$ \\
\hline 4 & $71,8 \mathrm{a}$ & $178 \mathrm{a}$ & $0,9 \mathrm{a}$ & $10 \mathrm{a}$ & $2 b$ & $190,54 \mathrm{a}$ & $68,02 \mathrm{a}$ \\
\hline 5 & $77,2 \mathrm{a}$ & $176 \mathrm{a}$ & $1,1 \mathrm{a}$ & $10 \mathrm{a}$ & $2 b$ & $187,92 \mathrm{a}$ & $66,13 \mathrm{a}$ \\
\hline 6 & $70,6 \mathrm{a}$ & $186 \mathrm{a}$ & $1,0 \mathrm{a}$ & $10 \mathrm{a}$ & $2 \mathrm{~b}$ & $197,05 \mathrm{a}$ & $73,60 \mathrm{a}$ \\
\hline 7 & 69,9 a & $154 \mathrm{a}$ & $0,9 \mathrm{a}$ & $9 a$ & $2 b$ & $182,03 \mathrm{a}$ & 59,49 a \\
\hline 8 & $77,7 \mathrm{a}$ & $179 \mathrm{a}$ & $1,2 \mathrm{a}$ & $11 \mathrm{a}$ & $3 a$ & $188,47 \mathrm{a}$ & $74,48 \mathrm{a}$ \\
\hline 9 & $73,9 \mathrm{a}$ & $171 \mathrm{a}$ & $1,0 \mathrm{a}$ & $9 \mathrm{a}$ & $2 b$ & $175,73 \mathrm{a}$ & $60,14 \mathrm{a}$ \\
\hline CV (\%) & 11,50 & 16,10 & 15,25 & 14,53 & 19,42 & 13,71 & 19,98 \\
\hline
\end{tabular}

Médias seguidas da mesma letra nas colunas não diferem entre si pelo teste Scott-Knott a 5\%.

T1- tiametoxan $(200 \mathrm{~mL}$ por $100 \mathrm{~kg}$ de sementes); T2- [abamectina + tiametoxan + fludioxonil] (500mL por 100kg de sementes); T3- [fipronil + tiofanatometilico + piraclostrobina] $(200 \mathrm{~mL}$ por $100 \mathrm{~kg}$ de sementes); T4- [imidacloprido + tiodicarbe] (250mL por $100 \mathrm{~kg}$ de sementes); T5- CruiserAdvanced ${ }^{\mathbb{R}}(200 \mathrm{~mL}$ por $100 \mathrm{~kg}$ de sementes); T6- carboxamida (150mL por $100 \mathrm{~kg}$ de sementes); T7- abamectina (100mL por $100 \mathrm{~kg}$ de sementes); T8- [metalaxyl-M + fludioxonil] (100mL por 100kg de sementes); T9- testemunha (sem tratamento). 


\section{REFERÊNCIAS}

ALMEIDA, A.S. et al. Bioativador no desempenho fisiológico de sementes de arroz. Revista Brasileira de Sementes, v.33, n.3, p.501-510, 2011. Disponível em: < http://dx.doi.org/10.1590/ S0101-31222011000300013>. Acesso em: 10 jan. 2014. doi: 10.1590/S0101-31222011000300013.

BALARDIN, R.S. et al. Tratamento de sementes com fungicidas e inseticidas como redutores dos efeitos do estresse hídrico em plantas de soja. Ciência Rural, v.41, n.7, p.1120-1126, 2011. Disponível em: <http://dx.doi.org/10.1590/S0103$84782011000700002>$. Acesso em: 20 jan. 2014. doi: 10.1590 S0103-84782011000700002.

BRASIL. Regras para análise de sementes. Ministério da Agricultura, Pecuária e Abastecimento. Secretária de Defesa Agropecuária. Brasília: Mapa/ACS, 2009. p.399.

CANTERI, M.G. et al. SASM - Agri: sistema para análise e separação de médias em experimentos agrícolas pelos métodos Scoft-Knott, Tukey e Duncan. Revista Brasileira de Agrocomputação, v.1, n.2, p.18-24, 2001. Disponível em: <http:// www.agrocomputacao.deinfo.uepg.br/dezembro2001/Arquivos/ RBACArtigo03.pdf>. Acesso em: 11 jan. 2014.

CASTRO, P.R.C. et al. Análise da atividade reguladora de crescimento vegetal de tiametoxam através de biotestes. Publicatio, v.13, n.3, p.25-29, 2007. Disponível em: <http://www. revistas2.uepg.br/index.php/exatas/article/viewFile/892/774>. Acesso em: 25 jan. 2014.

CASTRO, P.R.C.; et al. Bioativadores na agricultura. In GAZZONI, D.L. Tiametoxam: uma revolução na agricultura brasileira. Petrópolis, RJ; Vozes, 2008. p.115-122.
CLAVIJO, J. Tiametoxam: um nuevo concepto em vigor y productividad. 4th Edition, Arte Litográfico, Bogotá, 196p. 2008.

DAN, L.G.M. et al. Efeito de diferentes inseticidas sobre a qualidade fisiológica de sementes de soja. Global Science and Technology, v.3, n.1, p.50-57, 2010. Disponível em: <http://rioverde.ifgoiano.edu.br/ periodicos/index.php/gst/article/view/89>. Acesso em: 05 fev. 2014.

HENNING, A.A. Patologia e tratamento de sementes: noções gerais.2.ed.-Londrina:Embrapa Soja(Documentos 264).2005.52p.

LAUXEN, L.R. et al. Desempenho fisiológico de sementes de algodão tratadas com tiametoxam. Revista Brasileira de Sementes, v.32, n.3, p.61-68, 2010. Disponível em: <http://dx.doi. org/10.1590/S0101-31222010000300007>. Acesso em: 10 jan. 2014. doi: 10.1590/S0101-31222010000300007.

MENTEN, J.O.; MORAES, M.H.D. Tratamento de sementes: histórico, tipos, características e benefícios. Informativo ABRATES, v.20, n.3, p.52-71, 2010. Disponível em: <http://www. abrates.org.br/images/stories/informativos/v20n3/minicurso03. pdf $>$. Acesso em: 27 jan. 2014.

NIELSEN, M.E.; BARBER, S.A. Differences among genotypes of corn in the kinetics of P uptake. Agronomy Journal, v.70, n.5, p.695-698, 1978. Disponível em: <https://www.agronomy.org/ publications/aj/abstracts/70/5/AJ0700050695 access $=0 \&$ view $=p$ df $>$. Acesso em: 20 fev. 2014. doi: 10.2134/agronj1978.0002196 $2007000050001 x$. 